\title{
Food taboo among pregnant Ethiopian women: magnitude, drivers, and association with anemia
}

\author{
Shimels Hussien Mohammed', Hailu Taye ${ }^{2}$, Bagher Larijani ${ }^{3}$ and Ahmad Esmaillzadeh ${ }^{4,5,6^{*}}$
}

\begin{abstract}
Background: There are pervasive pregnancy-related food taboos and myths (PRFT) in Ethiopia. The evidence, however, is limited on whether PRFT contributes to the burden of maternal anemia. Thus, this study was aimed to determine the magnitude of PRFT, the reasons for adherence to PRFT, and the association of adherence to PRFT with anemia, among pregnant Ethiopian women.
\end{abstract}

Methods: The study was case-control in design and recruited a sample of 592 pregnant women attending antenatal care in four health facilities in Addis Ababa, Ethiopia. Participants were classified into anemic cases $(n=$ 187) and non-anemic controls $(n=405)$ based on their hemoglobin level. PRFT was assessed by the participants' subjective reporting of avoidance of certain food items during the current pregnancy due to taboo reasons. The specific types of food items avoided and the underlying reasons for the avoidance were also assessed. The relation of PRFT with anemia was evaluated by multiple logistic regression analysis, controlling for covariate factors.

Result: Almost a fifth of the study participants (18.2\%) avoided one or more food items due to PRFT. Adherence to PRFT was 26.2 and $14.6 \%$ among the anemic and the non-anemic individuals, respectively. The food items most avoided due to adherence to PRFT were green chili pepper, organ meat, and dark green leafy vegetables like spinach, lettuce, kale, and broccoli. The underlying reasons for the adherence to PRFT were largely traditionally held beliefs and misconceptions. After controlling for covariates, PRFT was significantly and independently associated with a higher odds of anemia [adjusted odds ratio $(A O R)=2.12,95 \%$ confidence interval $(C l)=1.32-3.42, P=0.002$ ].

Conclusion: PRFT might be contributing to the burden of maternal anemia in Ethiopia. It is time for public health authorities in Ethiopia to recognize PRFT as a public health risk, strengthen maternal nutrition counseling, and create public awareness of the consequences of PRFT.

Trial registration: ClinicalTrials.gov (NCT03251664), 16 August 2017.

Keywords: Dietary behavior, Food taboo, Pregnancy, Anemia, Ethiopia

\section{Introduction}

Anemia remains among the major threats to the health and survival of pregnant women. It is often linked to maternal mortality and poor fetal outcomes $[1,2]$. The progress of maternal anemia reduction has been slow and less

\footnotetext{
*Correspondence: a.esmaillzadeh@gmail.com

${ }^{4}$ Obesity and Eating Habits Research Center, Endocrinology and Metabolism Molecular Cellular Sciences Institute, Tehran University of Medical Sciences, Tehran, Iran

${ }^{5}$ Department of Community Nutrition, School of Nutritional Sciences and Dietetics, Tehran University of Medical Sciences, P.O. Box 14155-6117, Tehran, Iran

Full list of author information is available at the end of the article
}

promising globally [1]. Estimates show that $40 \%$ of pregnant women were anemic in the year 2016, declining by only three percentage points from the figure in 1990 (43\% prevalence) [3]. Reducing the burden of maternal anemia has been a priority public health agenda in Ethiopia, too. However, contrary to what could be expected, the recent years have seen an increasing trend in the prevalence of maternal anemia in Ethiopia, rising from $17 \%$ in 2011 to $24 \%$ in 2016 [4]. The rise was even more marked among neonates and infants [4].

Anemia is a multi-causal problem, with influences originating from both individual and community levels $[2$,

(c) The Author(s). 2019 Open Access This article is distributed under the terms of the Creative Commons Attribution 4.0 International License (http://creativecommons.org/licenses/by/4.0/), which permits unrestricted use, distribution, and 
5]. The socioeconomic and cultural contexts of the society in which individuals live influence their dietary behavior, including following food taboo [6]. Food taboo forbids eating certain food items; thus, limiting one's dietary diversity and quality, which may result in poor health and nutritional outcomes. The extent of the practice, as well as the specific food items avoided, varies from one community to another community. However, food taboo is generally more common among rural and less educated communities than among urban and more educated communities [6, 7]. Pregnant women also adhere to food taboos more strictly than non-pregnant women $[8,9]$. Pregnancy, in its own, makes pregnant women vulnerable to malnutrition due to the physiological rise in nutrient demand, which may not be adequately met by dietary intake. Thus, further restricting eating due to pregnancy-related food taboos and myths (PRFT) may seriously affect the health of the mother as well as the fetus [7, 8]. Evidence shows higher rates of cesarean section and complicated pregnancy among women adhering to PRFT. Taboo prohibiting the consumption of iron-rich food items, like meat, legumes, or dark green vegetables, might result in anemia in pregnant as well as non-pregnant women [5].

Previous studies done in Ethiopia reported the existence of pervasive PRFT, which may be contributing to the burden of maternal anemia in the country. However, the studies were mainly qualitative $[7,10,11]$; thus, less informative on whether adhering to PRFT was associated with increased risk of anemia, and the extent of this relationship if present. In a recent review of the nutritional habits of immigrant Ethiopian women in Australia, Vasilevski et al. [7] reported that the literature on nutritional knowledge of pregnant Ethiopian women was limited and called for more studies. Thus, in this study, we aimed to determine the magnitude (prevalence) of adherence to PRFT, the reasons for the adherence to PRFT, and the extent of association of adherence to PRFT with anemia status of pregnant Ethiopian women.

\section{Methods}

\section{Study setting and population}

This study was done in Addis Ababa, Ethiopia, among pregnant women attending antenatal care (ANC) in four public health centers and hospitals. Data were collected from October 2015 to February 2016, as part of a project to investigate the dietary and non-dietary determinants of anemia during pregnancy and lactation periods. The project was registered on ClinicalTrials.gov as https://clinicaltrials.gov/ct2/show/NCT03251664.

\section{Study design, sample size, and sampling procedure}

We followed a case-control study design and recruited a total of 592 pregnant women, 187 anemic cases and 405 non-anemic controls. The sample size was determined based on the following assumptions: (i) proportion of exposure among cases 0.27 and controls 0.40 , (ii) $1: 2$ cases to controls ratio, (iii) 10 and 15\% non-response rates among cases and controls, respectively, (iv) two-tailed 5\% level of significance, and (v) 80\% power. Participants were recruited by systematic random sampling scheme based on the ANC client flow of the participating health facilities.

\section{Study participant selection and allocation}

Blood samples from each study participants were taken and examined by the health professionals of the health facilities. Using the blood samples, the participant' hemoglobin $(\mathrm{Hb})$ level was determined by HemoCue $\mathrm{Hb}^{\circ} 201$ (HemoCue AB, Ängelholm, Sweden). Following the World Health Organisation (WHO) guideline [12], the $\mathrm{Hb}$ measures were adjusted for the mean altitude of the study area. The altitude adjusted $\mathrm{Hb}$ level was used to allocate participants into cases (anemic, $\mathrm{Hb}<11 \mathrm{~g} / \mathrm{dL}$ ) and controls (non-anemic, $\mathrm{Hb} \geq 11 \mathrm{~g} / \mathrm{dL}$ ) [12]. The health professionals working in the ANC units of the participating health facilities, together with the study data collectors, evaluated the individual's eligibility for the study, according to the inclusion and the exclusion criteria of the study. The inclusion criteria were laboratory-confirmed pregnancy status, $\mathrm{Hb}$ level measured and anemia status known, and residing in the study area. Individuals were excluded if they had any of the following conditions: (i) severe medical problem requiring hospital admission, (ii) history of major trauma, surgery, blood donation, or abortion in the last 12 months prior to the study, or (iii) currently breastfeeding. Assignment of participants into the two study groups, cases (anemic) and controls (not anemic), was done based on the participants' anemia status. The cases were recruited sequentially unless they were excluded due to any of the predefined exclusion conditions. For each included case, two consecutive controls were selected from those found not anemic and fulfilled the eligibility criteria. The flow chart of the sample selection and allocation process is presented by Fig. 1.

\section{Exposure variables}

PRFT was the main exposure variable of interest in this study. It was assessed by the participants' subjective reporting of food items avoided during the current pregnancy due to taboo reasons. To be included in the classification of the PRFT, the food item should have to fulfill all of the following criteria:

(i) The food item should be part of the individual's diet before becoming pregnant. Thus, food items not consumed by the individual before becoming 


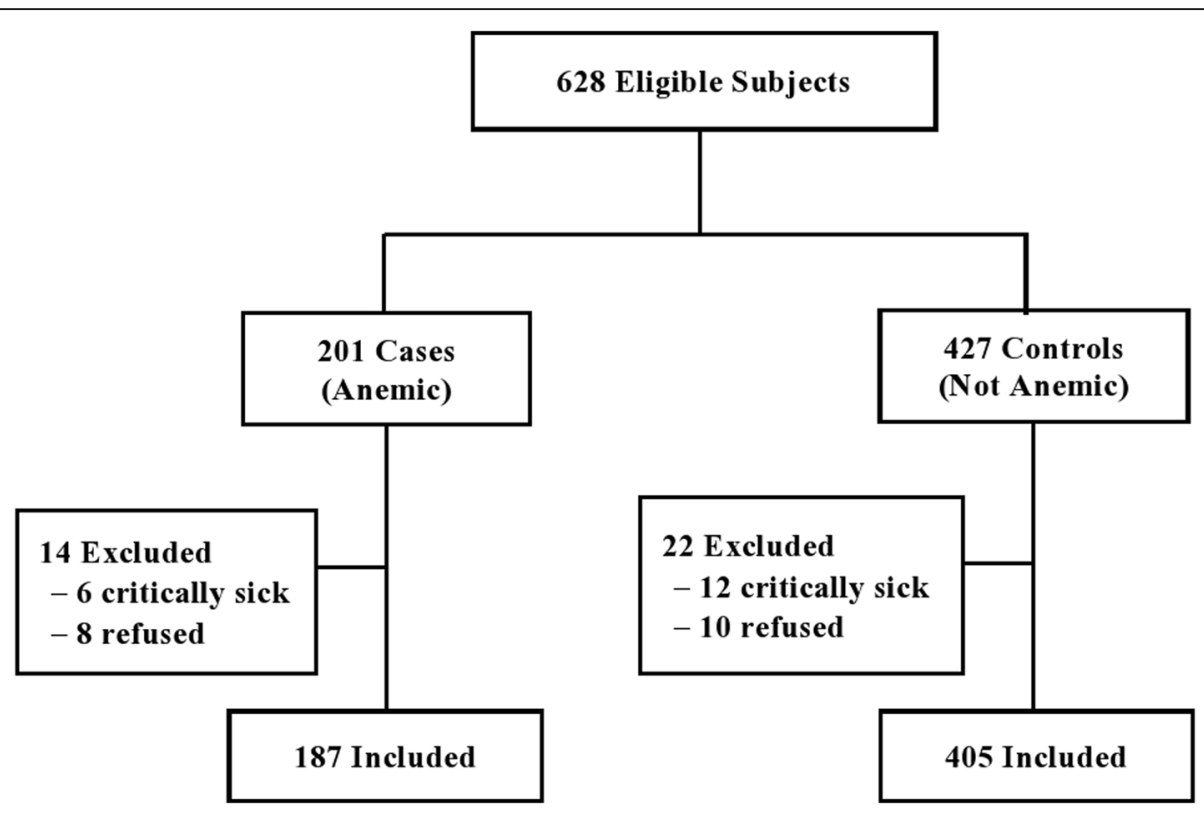

Fig. 1 Flowchart of the sample selection procedure

pregnant were not considered in the PRFT classification.

(ii) The food item should not be potentially unsafe during pregnancy. Thus, potentially unsafe food items like raw meat of any variety, and liver which might also be potential unsafe during pregnancy [13], were not considered in the PRFT classification.

(iii) The food item should not be culturally or religiously prohibited. For example, avoiding pork was not considered as PRFT as it was also a generally prohibited item by the community.

Based on their adherence to PRFT, the study participants were categorized into yes (adhering to PRFT) or no (not adhering to any PRFT). A further assessment of the reasons or beliefs for adhering to and practicing the PRFT was done, using a semi-structured interview guide. A comprehensive assessment of other potential determinants of anemia was also done, including the sociodemographic, reproductive, health, and nutritional status of the participants.

\section{Sociodemographic variables}

current age, educational status (measured by the highest education completed, and categorized into primary and below, secondary, tertiary and above), religion (categorized into Orthodox Christian, Muslim, others), and income (assessed by the average household monthly income and ranked into three categories: low, middle, high income categories). The classification of the participants into the low, middle and high-income categories was done by the relative position or ranking of the individual compared to the other individuals included in the study.

\section{Reproductive health variables}

gestational age (the pregnancy duration in months and categorized into three groups: first, second, third trimesters), gravidity (the number of conceptions including history of abortion, if any), and pregnancy interval (the duration from the last delivery to the conception of the current pregnancy).

\section{Health/nutrition variables}

history of chronic illness (assessed by the presence of any one of tuberculosis, Human Immunodeficiency Virus (HIV), or cancer), intestinal parasites (as reported by the lab stool examination), current use of iron/folate supplements, and hygiene practice (assessed by type of water source and toilet facilities used, and categorized into improved, unimproved). Weight, height, and mid-upper arm circumference (MUAC) measurements were also taken. MUAC is the preferred choice of assessment of the nutritional status of pregnant and lactating women. Thus, based on the MUAC measures, the nutrition status of the participants was classified into wasted (MUAC $<23 \mathrm{~cm}$ ) and normal (MUAC $\geq 23 \mathrm{~cm}$ ) [14].

\section{Statistical analyses}

First, the statistical assumptions for logistic regression analysis were checked. Then, bi-variable analyses between anemia and the exposure variables, including PRFT adherence, were done using Chi-square test of association. The bi-variable analyses were aimed to identify 
covariates which might influence the main relationship tested, i.e. the relation of PRFT with anemia. Thus, sociodemographic, reproductive, health, and nutrition variables which demonstrated $P<0.25$ during the bi-variable analyses were included in the final multiple logistic regression analysis. Adjusted odds ratios (AOR), with 95\% confidence intervals $(\mathrm{CI})$, were reported based on the results of the multiple regression analysis, done controlling for covariate factors. All analyses were done using STATA version 15 and statistical significance was determined at $P<0.05$, two-tailed.

\section{Result}

The sociodemographic characteristics of the study participants are shown in Table 1 . The majority of the participants $(\sim 70 \%)$ were below 30 years of age, with a mean age of 24.7 years ( $\mathrm{SD}=2.5$ years). Age of the participants ranged from 15 lowest to 39 highest. Religiously, $73.8 \%$ of the study participants were Orthodox Christians and 20\% Muslims. Only a quarter of the participants completed tertiary and above education levels.

Overall, $18.2 \%$ of the study participants avoided at least one food item during the current pregnancy due to PRFT. The prevalence among the anemic cases and non-anemic controls was 26.2 and $14.6 \%$, respectively. The items most avoided were green chili pepper, organ meat, and dark green leafy vegetables, which were avoided by 16.715 .7 , and $13.0 \%$ of the participants, respectively. The list of all food items avoided, with their percentage of avoidance, is found in Fig. 2. The dark green leafy vegetables group

Table 1 Sociodemographic characteristics of study participants

\begin{tabular}{lll}
\hline Variable & Category & Number (\%) \\
\hline Age group (year) & $15-19$ & $20(3.4)$ \\
& $20-24$ & $169(28.5)$ \\
& $25-29$ & $228(38.5)$ \\
& $30-34$ & $90(15.2)$ \\
& $35-39$ & $85(14.4)$ \\
Religion & Muslim & $119(20.1)$ \\
& Orthodox Christian & $437(73.8)$ \\
Marital status & Other & $36(6.1)$ \\
Occupation & Single & $24(4.1)$ \\
& Married & $568(95.9)$ \\
& Employed & $114(19.3)$ \\
& Merchant & $156(26.4)$ \\
Education level & Housewife & $183(30.9)$ \\
& Student & $82(13.9)$ \\
& Other & $57(9.6)$ \\
& Primary \& below & $238(40.1)$ \\
& Secondary & $198(33.5)$ \\
& Tertiary \& above & $156(26.4)$ \\
\hline
\end{tabular}

included food items like spinach, lettuce, kale, and broccoli. The organ meat group did not include liver, as it is not recommended during pregnancy. The food items least avoided were cereals and grains like wheat, maize, and corn. A third of the participants reported that they used to eat raw meat before becoming pregnant, but not eating currently due to fear of harming the fetus. The reasons for adhering to PRFT were fear of: (i) infection of the fetus as well as the mother, especially when eating vegetables; (ii) large baby and difficult birthing; (iii) offensive vaginal discharge; (iv) abortion; and (v) 'food sticking' on the fetus head, especially when eating banana.

Table 2 presents the results of the bivariate analyses between anemia and the exposure variables, including PRFT. Adherence to PRFT was significantly higher in the anemic than in the non-anemic individuals $(P=0.001)$. In terms of educational status, the anemic women were less educated than the non-anemic ones $(P<0.001)$. The proportion of low and middle-income individuals was higher among the anemic women than the non-anemic women $(P<0.001)$. In the second trimester, there were more non-anemic individuals than anemic individuals $(38.3 \%$ versus $10.7 \%$, $P<0.001)$. In the first trimester, there were more anemic individuals than non-anemic individuals $(42.2 \%$ versus $23.2 \%, P<0.001$ ). Wasting (MUAC $<23 \mathrm{~cm}$ ) was more prevalent in the anemic individuals than in the non-anemic individuals (36.9\% versus $23.5 \%, P=0.001$ ). There was no significant difference between the anemic individuals and the non-anemic individuals by gravidity, pregnancy interval, iron supplement use, intestinal parasites, chronic illness, and hygiene $(P>0.05)$.

Table 3 presents crude and adjusted ORs of the association of PRFT with anemia. The crude odds of anemia associated with adhering to PRFT was 2.08 times higher compared to that of not adhering to PRFT. To examine whether the association was independent of the influence of the covariates, i.e. confounding effect, AOR was calculated, controlling for the covariate factors identified during the bivariate analyses. There was no significant change in the strength of the PRFT-anemia association after controlling for education level, income, MUAC, gestational age, iron/folate supplement use, and chronic illness. Individuals adhering to PRFT were twice more likely to be anemic than those not adhering to PRFT $(\mathrm{AOR}=2.12$, $95 \% \mathrm{CI}=1.32-3.42, P=0.002$ ).

Some of the covariate variables were also found independently associated with anemia (Table 3). Low education level was associated with a significantly higher odds of anemia, such that individuals with primary and lower education level had a 3.3 times higher likelihood of being anemic, compared to those with tertiary education level $(\mathrm{AOR}=3.30,95 \% \mathrm{CI}=1.99-5.49, P<0.001)$. Compared to the high-income individuals, the odds of anemia was 1.86 and 2.2 times higher in the middle and the low-income 


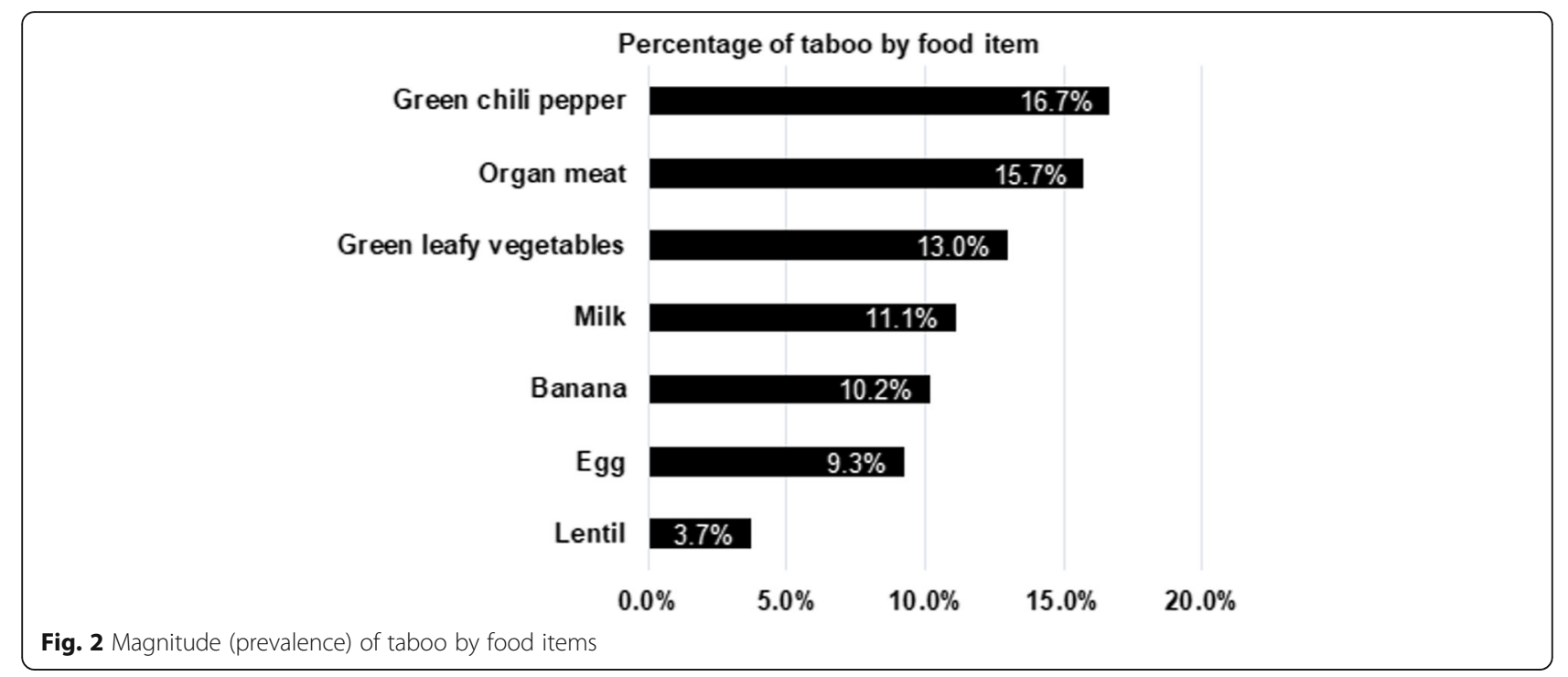

Table 2 Bivariate analysis of the relation of exposure variables and anemia status

\begin{tabular}{|c|c|c|c|c|}
\hline Variable & Category & Cases $^{\mathrm{a}} \mathrm{N}(\%)$ & Controls $^{\mathrm{b}} \mathrm{N}(\%)$ & $P^{*}$ \\
\hline \multirow[t]{2}{*}{ Food taboo } & Yes & $49(26.2)$ & $59(14.6)$ & 0.001 \\
\hline & No & $138(73.8)$ & $346(85.4)$ & \\
\hline \multirow[t]{3}{*}{ Education (year) } & Primary \& below & $105(56.5)$ & $132(32.6)$ & $<0.001$ \\
\hline & Secondary & $52(28.0)$ & $146(36.0)$ & \\
\hline & Tertiary \& above & $29(15.6)$ & $127(31.4)$ & \\
\hline \multirow[t]{3}{*}{ Income category } & Low & $73(39.0)$ & $109(26.9)$ & $<0.001$ \\
\hline & Middle & $70(37.4)$ & $123(30.4)$ & \\
\hline & High & $44(23.5)$ & $173(42.7)$ & \\
\hline \multirow[t]{3}{*}{ Trimester } & First & $79(42.2)$ & $94(23.2)$ & $<0.001$ \\
\hline & Second & $20(10.7)$ & $155(38.3)$ & \\
\hline & Third & $88(47.1)$ & $156(38.5)$ & \\
\hline \multirow[t]{2}{*}{ Gravidity } & $<=2$ & $123(65.8)$ & $267(65.9)$ & 0.971 \\
\hline & $>2$ & $64(34.2)$ & $138(34.1)$ & \\
\hline \multirow[t]{2}{*}{ Pregnancy interval } & $<2$ years & $61(32.6)$ & $133(32.8)$ & 0.958 \\
\hline & $>2$ years & $126(67.4)$ & $272(67.2)$ & \\
\hline \multirow[t]{2}{*}{ Iron supplement } & No & $155(82.9)$ & $317(78.3)$ & 0.194 \\
\hline & Yes & $32(17.1)$ & $88(21.7)$ & \\
\hline \multirow[t]{2}{*}{ Intestinal parasites } & No & $174(93.0)$ & $383(94.6)$ & 0.466 \\
\hline & Yes & $13(7.0)$ & $22(5.4)$ & \\
\hline \multirow[t]{2}{*}{ Chronic illness } & No & $176(94.1)$ & $390(96.3)$ & 0.162 \\
\hline & Yes & $11(5.9)$ & $15(3.7)$ & \\
\hline \multirow[t]{2}{*}{ MUAC (cm) } & $<=23$ & 69 (36.9) & $95(23.5)$ & 0.001 \\
\hline & $>23$ & $118(63.1)$ & $310(76.5)$ & \\
\hline \multirow[t]{2}{*}{ Hygiene practice } & Unimproved & $15(8.0)$ & $36(8.9)$ & 0.430 \\
\hline & Improved & $172(92.0)$ & 369 (91.1) & \\
\hline
\end{tabular}

${ }^{a}=$ Cases refer to the anemic group

$\mathrm{b}=$ Controls refer to the non-anemic group

*P: based on Chi-square test of association

MUAC, mid-upper arm circumference 
Table 3 Crude and adjusted estimates of the association of exposure variables with anemia

\begin{tabular}{|c|c|c|c|c|c|}
\hline \multirow[t]{2}{*}{ Variable } & & \multicolumn{2}{|l|}{ Crude OR } & \multicolumn{2}{|l|}{ Adjusted $\mathrm{OR}^{*}$} \\
\hline & & $\mathrm{OR}(95 \% \mathrm{Cl})$ & $P$ & AOR $(95 \% \mathrm{Cl})$ & $P^{* *}$ \\
\hline \multirow[t]{2}{*}{ Food taboo } & Yes & $2.08(1.36-3.19)$ & 0.002 & $2.12(1.32-3.42)$ & 0.002 \\
\hline & No & Reference & & Reference & \\
\hline \multirow[t]{3}{*}{ Education } & Primary & $3.48(2.16-5.62)$ & $<0.001$ & $3.30(1.99-5.49)$ & $<0.001$ \\
\hline & Secondary & $1.56(0.93-2.61)$ & 0.089 & $1.81(1.05-3.12)$ & 0.034 \\
\hline & Tertiary & Reference & & Reference & \\
\hline \multirow[t]{3}{*}{ Household income ${ }^{3}$} & Low & $2.63(1.69-4.11)$ & $<0.001$ & $2.20(1.36-3.57)$ & $<0.001$ \\
\hline & Middle & $2.24(1.44-3.48)$ & $<0.001$ & $1.86(1.15-3.01)$ & 0.012 \\
\hline & High & Reference & & Reference & \\
\hline \multirow[t]{2}{*}{ MUAC } & $\leq 23 \mathrm{~cm}$ & $1.91(1.31-2.78)$ & 0.001 & $1.53(1.01-2.33)$ & 0.047 \\
\hline & $>23 \mathrm{~cm}$ & Reference & & Reference & \\
\hline \multirow[t]{3}{*}{ Pregnancy trimester } & First & Reference & & Reference & \\
\hline & Second & $0.23(0.13-0.39)$ & $<0.001$ & $0.25(0.14-0.44)$ & 0.090 \\
\hline & Third & $1.49(1.00-2.22)$ & 0.049 & $1.44(0.95-2.20)$ & $<0.001$ \\
\hline \multirow[t]{2}{*}{ Iron supplement } & Yes & Reference & & Reference & \\
\hline & No & $0.74(0.47-1.16)$ & 0.195 & $1.06(0.64-1.73)$ & 0.829 \\
\hline \multirow[t]{2}{*}{ Chronic illness } & Yes & $1.63(0.73-3.61)$ & 0.233 & $1.41(0.60-3.33)$ & 0.430 \\
\hline & No & Reference & & Reference & \\
\hline
\end{tabular}

$A O R$, adjusted odds ratio; $O R$, odds ratio; $C l$, confidence interval; $M U A C$, mid-upper arm circumference

${ }^{*}$ Multiple logistic regression used to determine statistical significance

**Significant at $P<0.05$

individuals, respectively. In the wasted individuals, the likelihood of anemia was 1.53 times higher than that of the non-wasted individuals $(\mathrm{AOR}=1.53,95 \% \mathrm{CI}=1.01$ 2.33, $P=0.047$ ). The odds of anemia was also significantly higher during the third trimester, compared to the first trimester $(\mathrm{AOR}=1.44,95 \% \mathrm{CI}=0.95-2.20, P<0.001)$. However, iron supplement use and chronic illness were not significantly linked to anemia $(P>0.05)$.

\section{Discussion}

This study aimed to determine the magnitude adherence to PRFT, the reasons for adhering to PRFT, and the extent at which PRFT was linked to anemia, among pregnant Ethiopian women. We found a considerable portion of the study participants avoiding certain food items of significant importance for the health of the mother as well as the fetus. We also found that PRFT was independently associated with a significantly higher odds of anemia.

Almost a fifth the participants involved in this study avoided one or more food items due to adhering to PRFT. Studies done in Kenya [9] and Mexico [15] among a similar population of women reported PRFT magnitude of 60 and $50.3 \%$, respectively. The low magnitude of PRFT among our study participants might be because it was conducted in an urban setting. Green chili pepper, organ meat, and dark green leafy vegetables were more commonly avoided than other food items like cereals. Previous studies done in Ethiopia $[7,11]$ as well as other developing countries $[8,9,15]$ also reported a high avoidance of meat and vegetables by pregnant and lactating women due to taboo. A third of our study participants reported as they used to eat raw meat but stopped after becoming pregnant. Eating raw meat, particularly strips of fresh beef and lamb in various forms, is a pervasive practice in Ethiopia. However, because eating meat raw is unsafe, we did not consider its avoidance as a taboo or PRFT. Food taboos could hinder individuals from consuming certain food items [7]. This may result in poor dietary quality and diversity, which may subsequently lead to poor health and nutritional outcomes including anemia $[7,8,16]$. Thus, our finding of the association of anemia with PRFT could be in part due to the above reason, i.e. poor dietary quality due to taboo. A further plausible explanation for our finding was that the most avoided food items like organ meat, lentil, and dark green leafy vegetables, are of a better iron profile compared to the least avoided food items like wheat and corn [5].

We believe our finding of the association of PRFT with anemia might, in part, account for the current state of anemia in Ethiopia. Progress in reducing maternal anemia has been less promising in Ethiopia. Instead of decline, it is on the rise across all age groups, regions and sex [4]. Iron deficiency anemia (IDA) was presumed to be the main driver of the global burden of anemia. It 
was often considered to account for almost half of the global anemia burden $[2,5]$. Thus, iron supplementation has taken the centrality of anemia prevention and control interventions in many countries, including Ethiopia [17]. However, recent evidence has shown that the contribution of IDA to anemia is not as high as the widely held presumption $[18,19]$. It could be even insignificant in Ethiopia due to a set of dietary and genetic conditions, unique to Ethiopians [20-22]. However, notwithstanding the importance of iron supplementation during pregnancy, our finding of an independent association of PRFT with anemia might imply that PRFT needs to be addressed to curb the burden of anemia in Ethiopia.

Though not the main objective of the study, use of iron supplement was not found significantly associated with anemia. As iron is an important nutrient for erythropoiesis [5], use of iron supplement is normally expected to correlate with an improved hemoglobin level. Notwithstanding that, there are many plausible explanations for the finding. First, our analysis did not take into account the adherence and duration of the iron supplement use. These factors will influence the level of hematologic response to iron supplement use [5]. Second, most of the participants may not have been iron deficient. Some studies have shown that iron deficiency is not a major problem in Ethiopia [19, 21, 23]. Third, it could be related to some unique environmental, genetic, and dietary factors which might influence the absorption, transport, and metabolism of iron $[20,22,23]$. The validity of the WHO hemoglobin cutoff points for highland populations, including Ethiopia, is also questionable $[24,25]$. Thus, as the case of anemia in Ethiopia has not been well investigated, it would be hard to state the specific reason that is most responsible for the lack of association of iron supplement use with anemia among our study participants.

This study has important policy implications. There is low awareness among Ethiopian women about the pregnancy-related changes in nutrient demand and the dietary recommendations to meet the changing demands [7]. This might be due to the poor integration of nutrition services with the existing health care system in the country. For example, nutritionist or dieticians are not included in the Ethiopian hospitals' workforce [26]. The dietary information provided by other professionals might be incomplete and vague. This might also be the reason for the low awareness of Ethiopian mothers on the negative consequences of food taboo $[7,11]$. Thus, it stands important for health facilities in Ethiopia to consider integrating nutrition care and support with the existing system. ANC visits, in particular, are great opportunities to reach pregnant women, address PRFT, and avert its consequences on the mother as well as the fetus. Pregnancy is a critical period for both the mother and the fetus as the effects of nutritional deficiencies during this period could be irreversible
[17]. Compared to non-pregnant women, pregnant women are more receptive to nutritional advice and also more willing to change their eating behavior $[7,16]$. In addition to strengthening the institutional nutritional services, public awareness creation also stands an important consideration. In general, Ethiopian women are already at higher risks of complicated pregnancy [7], maternal mortality, and anemia [4]. PRFT may further aggravate the vulnerability to these risks. Thus, it is time for the Ministry of Health of Ethiopia to consider food taboo as a public health challenge and design appropriate interventions.

The study has some limitations worth presenting to the reader. The design, case-control, precludes making causal inference or ruling out reverse causality. It would be beneficial to repeat these analyses using data from prospective studies to strengthen our conclusions. We did not evaluate the association of anemia with each of the specific food items avoided. Thus, the strength of the PRFT-anemia association may change by the specific food items avoided as hematologic response to food varies by the type of food item. Thus, the estimate we reported might not be applicable to any of the specific food items. The study was done using hospital-based samples, which would be limiting its generalizability to the whole population. The women attending ANC visits might be different from those not attending ANC, which would further undermine the generalizability of the findings. We did not collect data on the pattern of food replacement due to the PRFT. Thus, we could not examine whether the replacement, if any, affects the association of PRFT with anemia. Future researchers are encouraged to investigate the pattern of replacement as well as its influence on health in general and anemia in particular. The main strength of the study was that it addressed a neglected problem of public health importance. The comprehensive adjustment for various factors might have minimized the possibility that the observed association was confounded.

\section{Conclusion}

There was a concerning level of adherence to PRFT among pregnant Ethiopian women living in Addis Ababa. Green chili pepper, organ meat, and dark green leafy vegetables were the most avoided food items, with the reasons for the avoidance being largely traditionally held myths and misinformation. PRFT was significantly and independently associated with a moderately higher likelihood of anemia. Thus, PRFT might be among the factors contributing to the burden of maternal anemia in Ethiopia. Further prospective studies are warranted to provide better evidence on the exact contribution PRFT to the burden of anemia. However, as adherence to PRFT is often harmful, it is time for public health authorities in Ethiopia to recognize and address the problem. To that end, strengthening maternal 
nutrition counseling and creating public awareness of the consequences of PRFT represents worthy of consideration.

\section{Abbreviations}

ANC: Antenatal care; AOR: Adjusted odds ratio; Cl: Confidence interval; Hb: Hemoglobin; MUAC: Mid-upper arm circumference; OR: Odds ratio; PRFT: Pregnancy-related food taboo; SD: Standard deviation; WHO: World Health Organization

\section{Acknowledgments}

SHM is a recipient of a postgraduate scholarship, Tehran University of Medical Sciences-International Campus (TUMS-IC). We are grateful for the study participants and the health facilities participated.

\section{Funding}

This research received no specific grant from any funding agency in public, commercial or not-for-profit sectors.

\section{Availability of data and materials}

The dataset used and analyzed during the current study is available from the corresponding author on a reasonable request.

\section{Authors' contribution}

SHM, and HKT conceived and led the study. HKT managed the data collection. SHM conducted data cleaning, analysis, and manuscript writing. $\mathrm{AE}$ and $\mathrm{BL}$ supervised the study and critically reviewed the draft manuscript. All authors read and approved the final manuscript.

\section{Ethics approval and consent to participate}

The study was approved by the Institutional Review Boards (IRB) of University of Gondar and Addis Ababa City Health Bureau, (Ref: AAHB-217/ 15). A written letter of permission to conduct the study was obtained from Addis Ababa City Health Bureau. Besides, the participating health facilities were informed about the study and the study participants provided written consent of participation in the study and sharing of findings based on the information collected. The data collectors counseled the study subjects on nutritional recommendations during pregnancy and advised those found anemic to seek further medical care. The study was registered on American ClinicalTrials.gov as https://clinicaltrials.gov/ct2/show/NCT03251664.

\section{Consent for publication}

The study participants provided consent for communicating the findings based on the information they provided, including through publications.

\section{Competing interests}

The authors declared no competing interests.

\section{Publisher's Note}

Springer Nature remains neutral with regard to jurisdictional claims in published maps and institutional affiliations.

\footnotetext{
Author details

${ }^{1}$ Department of Community Nutrition, School of Nutritional Sciences and Dietetics, Tehran University of Medical Sciences-International Campus (TUMS-IC), Tehran, Iran. ${ }^{2}$ Unit of Reproductive Health, Addis Ababa City Administration Health Bureau, Addis Ababa, Ethiopia. ${ }^{3}$ Endocrinology and Metabolism Research Center, Endocrinology and Metabolism Clinical Sciences Institute, Tehran University of Medical Sciences, Tehran, Iran. ${ }^{4}$ Obesity and Eating Habits Research Center, Endocrinology and Metabolism Molecular Cellular Sciences Institute, Tehran University of Medical Sciences, Tehran, Iran. ${ }^{5}$ Department of Community Nutrition, School of Nutritional Sciences and Dietetics, Tehran University of Medical Sciences, P.O. Box 14155-6117, Tehran, Iran. ${ }^{6}$ Food Security Research Center, Department of Community Nutrition, Isfahan University of Medical Sciences, Isfahan, Iran.
}

Received: 18 November 2018 Accepted: 18 March 2019

Published online: 23 March 2019

\section{References}

1. Allard S. Anaemia in pregnancy--a renewed focus needed. BJOG. 2015; 122(2):169.

2. Stevens GA, Finucane MM, De-Regil LM, Paciorek CJ, Flaxman SR, Branca F, et al. Global, regional, and national trends in haemoglobin concentration and prevalence of total and severe anaemia in children and pregnant and non-pregnant women for 1995-2011: a systematic analysis of populationrepresentative data. Lancet Glob Health. 2013;1(1):e16-25.

3. World Health Organization. World Health Statistics. https://data.worldbank. org/indicator/SH.PRG.ANEM. Accessed 20 October 2018.

4. Central Statistical Agency [Ethiopia] and ICF International. Ethiopia Demographic and Health Survey 2016. https://dhsprogram.com/pubs/pdf/ FR328/FR328.pdf. Accessed 20 June 2018.

5. Camaschella C. Iron-deficiency Anemia. N Engl J Med. 2015;373(5):485-6.

6. Meyer-Rochow VB. Food taboos: their origins and purposes. J Ethnobiol Ethnomed 2009, 5:18-18.

7. Vasilevski V, Carolan-Olah M. Food taboos and nutrition-related pregnancy concerns among Ethiopian women. J Clin Nurs. 2016;25(19-20):3069-75.

8. Kavle JA, Landry M. Addressing barriers to maternal nutrition in low- and middle-income countries: A review of the evidence and programme implications. Maternal \& Child Nutrition 2018, 14(1).

9. Riang'a RM, Broerse J, Nangulu AK. Food beliefs and practices among the Kalenjin pregnant women in rural Uasin Gishu County. Kenya Journal of Ethnobiology and Ethnomedicine. 2017;13(1):29.

10. Hadush Z, Birhanu Z, Chaka M, Gebreyesus H. Foods tabooed for pregnant women in Abala district of Afar region, Ethiopia: an inductive qualitative study. BMC Nutrition. 2017:3(1):40.

11. Zerfu TA, Umeta M, Baye K. Dietary habits, food taboos, and perceptions towards weight gain during pregnancy in Arsi, rural Central Ethiopia: a qualitative cross-sectional study. J Health Popul Nutr 2016, 35(1):22-22.

12. World Health Organization. Haemoglobin concentrations for the diagnosis of anaemia and assessment of severity. 2011. http://apps.who.int/iris/ handle/10665/85839. Accessed 20 October 2018.

13. Simpson JL, Bailey LB, Pietrzik K, Shane B, Holzgreve W. Micronutrients and women of reproductive potential: required dietary intake and consequences of dietary deficiency or excess. Part II--vitamin D, vitamin a, iron, zinc, iodine, essential fatty acids. J Matern Fetal Neonatal Med. 2011;24(1):1-24.

14. Ververs M-T, Antierens A, Sackl A, Staderini N, Captier V. Which anthropometric indicators identify a pregnant woman as acutely malnourished and predict adverse birth outcomes in the humanitarian context? PLoS currents. 2013:5:ecurrents.dis. 54a58b618c611bc031ea140e613f2934599c2934598.

15. Santos-Torres MI, Vasquez-Garibay E. Food taboos among nursing mothers of Mexico. J Health Popul Nutr. 2003;21(2):142-9.

16. Daba G, Beyene F, Fekadu H, Garoma W. Assessment of knowledge of pregnant mothers on maternal nutrition and associated factors in Guto Gida Woreda, east Wollega zone, Ethiopia. J Nutr Food Sci. 2013;3(6):1.

17. Bhutta ZA, Das JK, Rizvi A, Gaffey MF, Walker N, Horton S, et al. Evidencebased interventions for improvement of maternal and child nutrition: what can be done and at what cost? Lancet. 2013;382(9890):452-77.

18. Petry N, Olofin I, Hurrell RF, Boy E, Wirth JP, Moursi M, et al. The proportion of Anemia associated with Iron deficiency in low, medium, and high human development index countries: a systematic analysis of National Surveys. Nutrients. 2016:8(11):693.

19. Harika R, Faber M, Samuel F, Kimiywe J, Mulugeta A, Eilander A. Micronutrient Status and Dietary Intake of Iron, Vitamin A, lodine, Folate and Zinc in Women of Reproductive Age and Pregnant Women in Ethiopia, Kenya, Nigeria and South Africa: A Systematic Review of Data from 2005 to 2015. Nutrients. 2017;9(10).

20. Alkorta-Aranburu G, Beall CM, Witonsky DB, Gebremedhin A, Pritchard JK, Di Rienzo A. The genetic architecture of adaptations to high altitude in Ethiopia. PLoS Genet. 2012;8(12):e1003110.

21. Gebreegziabher T, Stoecker BJ. Iron deficiency was not the major cause of anemia in rural women of reproductive age in Sidama zone, southern Ethiopia: a cross-sectional study. PLoS One. 2017;12(9):e0184742.

22. Mohammed SH, Taye H, Sissay TA, Larijani B, Esmaillzadeh A. Teff consumption and anemia in pregnant Ethiopian women: a case-control study. Eur J Nutr. 2018 
23. Gebre-Medhin M, Killander A, Bahlquist B, Wuhib E. Rarity of anaemia of pregnancy in Ethiopia. Scand J Haematol. 1976;16(3):168-75.

24. Gonzales GF, Rubín de Celis V, Begazo J, Del Rosario Hinojosa M, Yucra S, Zevallos-concha A, et al. Correcting the cut-off point of hemoglobin at high altitude favors misclassification of anemia, erythrocytosis and excessive erythrocytosis. Am J Hematol. 2018;93(1):E12-6.

25. Gonzales GF, Fano D, Vasquez-Velasquez C. Diagnosis of anemia in populations at high altitudes. Revista peruana de medicina experimental y salud publica. 2017;34(4):699-708

26. Ministry of Health Ethiopia. Fact sheet about heath status in Ethiopia. 2015. http://www.moh.gov.et/es/web/guest/fact-sheets. Accessed 28 February 2019.

Ready to submit your research? Choose BMC and benefit from:

- fast, convenient online submission

- thorough peer review by experienced researchers in your field

- rapid publication on acceptance

- support for research data, including large and complex data types

- gold Open Access which fosters wider collaboration and increased citations

- maximum visibility for your research: over $100 \mathrm{M}$ website views per year

At $\mathrm{BMC}$, research is always in progress.

Learn more biomedcentral.com/submissions 